\title{
Heartbeat: blood pressure and left ventricular remodelling in young athletes
}

doi:10.1136/heartjnl-2019-315684

Pre-participation screening of athletes mostly has focused on identifying those at increased risk of sudden cardiac death. However, screening also offers an opportunity for primary prevention of cardiovascular disease. In a large cohort of young (age 13-35 years) athletes, Hedman and colleagues ${ }^{1}$ looked at the prevalence of hypertension as defined by US/European guidelines and the associations between blood pressure (BP) and left ventricular (LV) remodelling in these subjects. Overall, $34.3 \%$ of athletes had a BP that exceeded US hypertension thresholds. Independent correlates of BP were male sex, body mass index and height. In the subset of subjects with ECG data, systolic BP was independently associated with a higher LV mass/volume ratio and with slower early diastolic relaxation. The relationship between mean systolic BP, age and specific sports is shown in figure 1 .

In an editorial, Stöhr and colleagues ${ }^{2}$ point out that 'The clear linear association between blood pressure and LV mass/ volume ratio at subclinical levels indicates that the biological progression occurs on a continuum and applying categorical cut-offs may not be in the best interest. Instead, the data support the need to increase our understanding of specific cardiovascular phenotypes associated with increased blood pressure, in particular in an otherwise low-risk, young population.'

Severe tricuspid regurgitation (TR) increasingly is recognised as contributing to cardiovascular symptoms and mortality yet management remain controversial. In this issue of Heart, Ingraham and colleagues ${ }^{3}$ from the Mayo Clinic report on the clinical presentation and outcomes of 87 adults with severe TR who were considered for intervention over a $2 \frac{1}{2} 2$-year period (figure 2). These patients are a challenging groupmean age was 80 years, all were severely symptomatic, nearly all were in atrial fibrillation, most had chronic kidney disease and about $1 / 2$ had right ventricular systolic dysfunction. Only about $1 / 4$ of patients underwent tricuspid valve

Correspondence to Professor Catherine M Otto, Division of Cardiology, University of Washington, Seattle, WA 98195, USA; cmotto@uw.edu

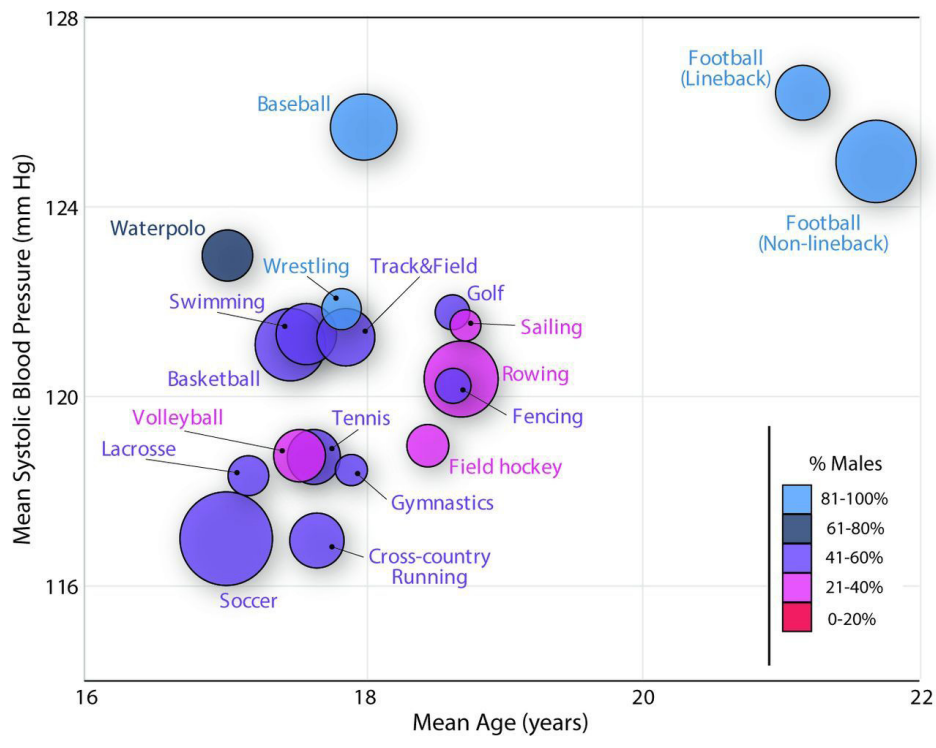

Figure 1 Mean systolic blood pressure in all sports with $\geq 40$ athletes, in relation to average age per sport. Circle area is proportional to the number of athletes in each sports category (reference: sailing $n=40$, soccer $n=368$ ) and circle colour indicates the proportion of males in each sport category, as explained in imposed legend.

intervention (transcatheter device in 13 and surgical repair/replacement in 9), typically those with more severe TR, more severe symptoms and better right

ventricular function. Survival at 1 year was not significantly different in those managed medically compared those with an intervention ( $73 \%$ vs $88 \%)$.

\section{Severe TR Survival}

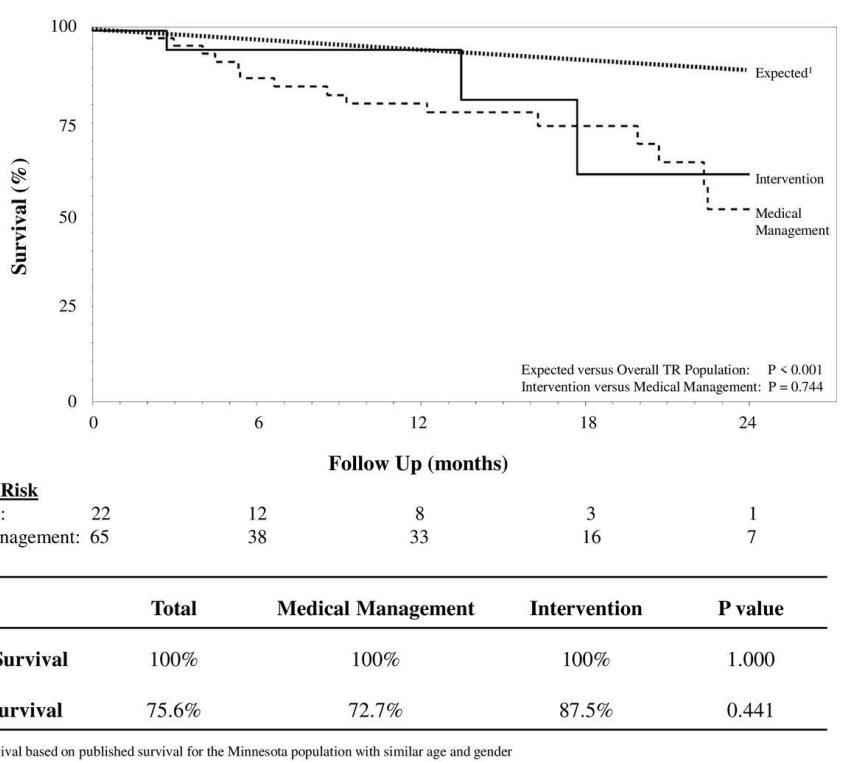

Figure 2 Survival of study population by group and compared with expected survival. TR, tricuspid regurgitation. 


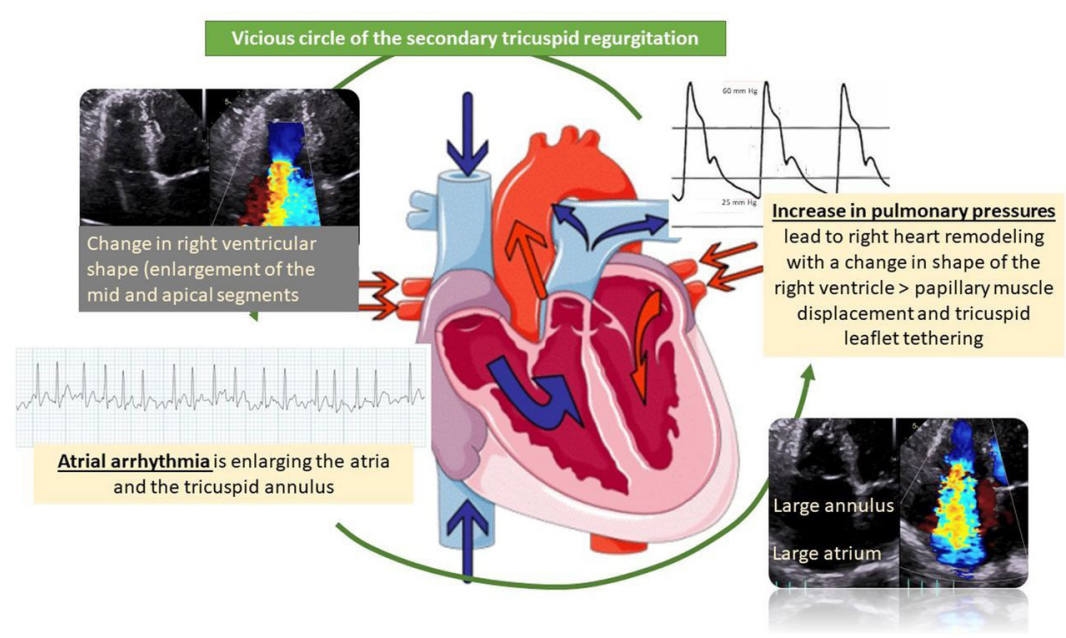

Figure 3 Vicious circle of the secondary tricuspid regurgitation.

Despite the difficulties in managing patients with severe TR, Donal and colleagues ${ }^{4}$ argue that we should push ahead with randomised controlled trials of interventions to reduce TR with the goal of improving patient symptoms and survival. They conclude that 'We should not forget that secondary TR is a strong prognostic marker but is secondary to annular and right heart dilatation, and we should probably not wait for the right heart disease to be too advanced to consider correction of TR. As for other valvular disease, TR induces a vicious circle. It should probably be stopped as soon as the diagnosis of severe TR is made (figure 3 ).'

Elevated troponin measurements show that myocardial infarction in patients with non-obstructive coronary artery disease (MINOCA) accounts for about 10\% of patients undergoing urgent coronary angiography. Bhatia and colleagues ${ }^{5}$ reviewed 215 patients with cardiac magnetic resonance (CMR) imaging within 30 days of MINOCA and found evidence for myocarditis in $32 \%$, a small infarction in $22 \%$, a non-ischaemic cardiomyopathy in $20 \%$ and stress cardiomyopathy in 9\%. The remaining $17 \%$ had no CMR abnormality to explain an elevated troponin.

Sechtem and colleagues ${ }^{6}$ comment that 'the study by Bhatia et $\mathrm{al}^{5}$ confirms in a large number of carefully studied patients that myocarditis and small myocardial infarcts are frequent in patients with MINOCA. Furthermore, CMR if performed early after

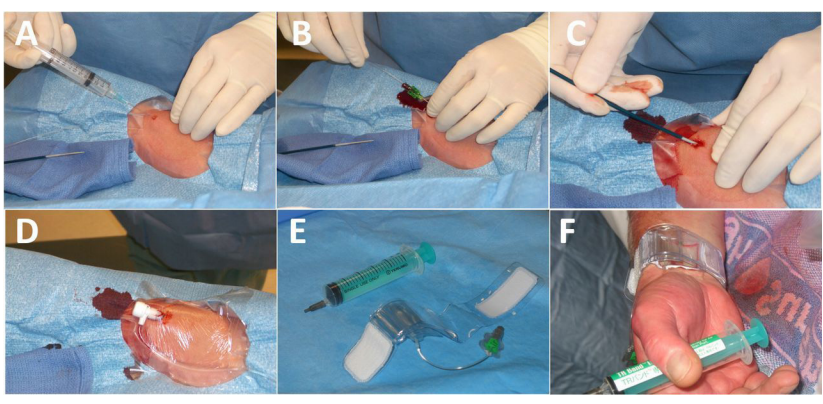

Figure 4 Radial artery access technique and postprocedure haemostasis. (A) Administration of subcutaneous local anaesthetic. (B) Micropuncture needle is slowly advanced at a $30^{\circ}-45^{\circ}$ trajectory until the anterior wall is punctured. Once the luminal position is confirmed by the flow of arterial blood from the hub, the guidewire is inserted. (C) The micropuncture needle is removed and a tapered hydrophilic-coated radial sheath is inserted over the guidewire. (D) Sheath is flushed and secured. (E) Transradial band (Terumo, Japan) radial compression bracelet with syringe. (F) Band is positioned by aligning green marker $1-2 \mathrm{~mm}$ proximal to the puncture site. Air is injected into compression balloon while sheath is removed. Aim to achieve patent haemostasis. the event as in this study will still capture cases of takotsubo syndrome. The mechanism of MINOCA in patients with cardiomyopathies and those with normal CMR findings remains unclear. A combination of coronary function testing and CMR will most likely yield the best diagnostic and therapeutic results.'

The Education in Heart article in this issue $^{7}$ provides a tutorial on vascular access and closure for cardiovascular intervention. Radial artery access now is the preferred approach and this article details the optimal technique to avoid complications (figure 4). Femoral artery access is used less commonly but interventional cardiologists still need to be proficient in this approach as alternate access is needed in some patients.

The Cardiology in Focus article in this issue provides information about the British Cardiovascular Intervention Society database with links for those interested in accessing the data and public reports of UK operator and centre case mix and outcomes. $^{8}$

\section{Competing interests None declared.}

Patient consent for publication Not required.

Provenance and peer review Commissioned; internally peer reviewed.

(c) Author(s) (or their employer(s)) 2019. No commercial re-use. See rights and permissions. Published by BMJ.

\section{Check for updates}

To cite Otto CM. Heart 2019;105:1215-1216.

Heart 2019;105:1215-1216.

doi:10.1136/heartjnl-2019-315684

\section{REFERENCES}

1 Hedman K, Moneghetti KJ, Christle JW, et al. Blood pressure in athletic preparticipation evaluation and the implication for cardiac remodelling. Heart 2019:105:1223-30.

2 Stöhr EJ, McDonnell BJ. Cockcroft jr young athletes under pressure? Heart 2019;105:1217-8.

3 Ingraham BS, Pislaru SV, Nkomo VT, et al. Characteristics and treatment strategies for severe tricuspid regurgitation. Heart 2019;105:1244-50.

4 Donal E, Galli E, Bidaut A. Advocacy for more consideration of the secondary tricuspid regurgitation. Heart 2019:105:1221-2.

5 Bhatia S, Anstine C, Jaffe AS, et al. Cardiac magnetic resonance in patients with elevated troponin and normal coronary angiography. Heart 2019:105:1231-6.

6 Sechtem U, Seitz A, Ong P. MINOCA: unravelling the enigma. Heart 2019;105:1219-20.

7 Dorman SH, Obaid DR. Vascular access and closure for cardiovascular intervention. Heart 2019:105:1279-88.

8 Ludman P. British cardiovascular intervention Society database: insights into interventional cardiology in the United Kingdom. Heart 2019;105:1289. 